\title{
The Effect of Annealing Temperatures on Selected Properties of WC/C Coatings, Deposited Using Hexacarbonyl Wolfram in an $\mathrm{N}_{2}-\mathrm{SiH}_{4}$ Atmosphere
}

\author{
Peter Horňák ${ }^{1,2}$, Daniel Kottfer ${ }^{3, *}$, Karol Kyziol $^{4}{ }^{\oplus}$, Marianna Trebuňová ${ }^{5}\left(\mathbb{D}\right.$, Mária Kaňuchová $^{6}$, \\ Lukasz Kaczmarek $^{7}$, Jozef Jasenák ${ }^{3}$, Ján Hašul' ${ }^{8}$ (1) and Lukáš Rusinko ${ }^{8}$
}

\section{check for} updates

Citation: Horňák, P.; Kottfer, D.; Kyzioł, K.; Trebuňová, M.;

Kaňuchová, M.; Kaczmarek, L.; Jasenák, J.; Hašul', J.; Rusinko, L. The Effect of Annealing Temperatures on Selected Properties of WC/C Coatings, Deposited Using Hexacarbonyl Wolfram in an $\mathrm{N}_{2}-\mathrm{SiH}_{4}$ Atmosphere. Materials 2021, 14, 4658. https://doi.org/10.3390/ma14164658

Academic Editor: Evgeny Levashov

Received: 14 June 2021

Accepted: 14 August 2021

Published: 18 August 2021

Publisher's Note: MDPI stays neutral with regard to jurisdictional claims in published maps and institutional affiliations.

Copyright: (C) 2021 by the authors. Licensee MDPI, Basel, Switzerland. This article is an open access article distributed under the terms and conditions of the Creative Commons Attribution (CC BY) license (https:/ / creativecommons.org/licenses/by/ $4.0 /$ )
1 Department of Materials Science, Faculty of Industrial Technologies, Alexander Dubček University of Trenčín, I. Krasku 491/30, 02001 Púchov, Slovakia; hornak.peter@gmail.com

2 Slovak Academy of Sciences, Institute of Materials Research, Watsonova 47, 04001 Košice, Slovakia

3 Department of Mechanical Technologies and Materials, Faculty of Special Technology, Alexander Dubček University of Trenčín, Ku Kyselke 469, 91106 Trenčín, Slovakia; jozef.jasenak@tnuni.sk

4 Faculty of Materials Science and Ceramics, AGH University of Science and Technology, A. Mickiewicza 30 Av., 30-059 Kraków, Poland; kyziol@agh.edu.pl

5 Department of Biomedical Engineering and Measurement, Faculty of Mechanical Engineering, Technical University of Košice, Letná 9, 04200 Košice, Slovakia; marianna.trebunova@tuke.sk

6 Process Control and Geotechnology, e Institute of Mountainous Sciences and Environmental Protection, Faculty of Mining, Ecology, Technical University of Košice, Park Komenskeho 19, 04384 Košice, Slovakia; maria.kanuchova@tuke.sk

7 Institute of Materials Science and Engineering, Lodz University of Technology, 1/15 Stefanowskiego Str., 90-924 Łódź, Poland; lukasz.kaczmarek@p.lodz.pl

8 Department of Technologies, Materials and Computer Aided Production, Faculty of Mechanical Engineering, Technical University of Košice, Mäsiarska 74, 04001 Košice, Slovakia; jan.hasul@tuke.sk (J.H.); lukas.rusinko@student.tuke.sk (L.R.)

* Correspondence: daniel.kottfer@tnuni.sk; Tel.: +421-327-400-203

Abstract: In this paper, we present the results of an experimental study on WC/C coatings, deposited by using plasma-enhanced chemical vapor deposition in an $\mathrm{N}_{2}-\mathrm{SiH}_{4}$ atmosphere, annealed at temperatures of 200,500 and $800{ }^{\circ} \mathrm{C}$, in which the hexacarbonyl of $\mathrm{W}$ was used as a precursor. During the experiments, the topography, chemical composition, morphology, as well as selected mechanical properties, such as hardness, Young's modulus, and coefficient of friction of the WC/C coatings were analyzed. Annealing without the protective atmosphere in the mentioned temperatures caused a decrease in hardness (up to $15 \pm 2.7 \mathrm{GPa}$ ). In addition, the coefficient of friction value increased only to $0.37 \pm 0.03$.

Keywords: WC/C coating; hexacarbonyl wolfram; plasma enhanced chemical vapor deposition; plasma; annealing; surface properties

\section{Introduction}

Tungsten carbide (WC) is often used as a thin coating, characterized by high values of hardness (42 GPa [1-3]), wear resistance, as well as a low coefficient of friction (COF, $0.22[1,2])$, whereas the surface hardness of unmodified steel is $5 \mathrm{GPa}$ [4]. Therefore, WC is often applied for the protection of functional surfaces of machining components made of steel, and for coating high-speed steel. WC can be deposited using the physical vapor deposition (PVD) method; WC's melting point is notably high $\left(2870{ }^{\circ} \mathrm{C}\right)$ [5]. Deposition techniques, in many instances, include direct current magnetron sputtering (DCMS) [6-13] and radio frequency magnetron sputtering (RFMS) [1,14-18]. Reactive sputtering using W, C, or WC target is frequently carried out with additional gases, such as hydrocarbon [6], $\mathrm{N}_{2}$, or $\mathrm{SiH}_{4}[7,8,17]$. In addition to other existing progressive PVD sputtering methods, two other methods for such WC coatings are high target utilization sputtering (HiTUS) [18], 
high-power impulse magnetron sputtering (HiPIMS) [7], and the chemical vapor deposition (CVD) technique $[19,20]$.

Importantly, during the coating deposition process using CVD (also called hightemperature HT CVD) methods, the temperature of the process changes from 800 to $1200{ }^{\circ} \mathrm{C}$, which excludes some steels and $\mathrm{Al}$ alloys from the deposition process.

The deposition temperature can be decreased using transitive gases, which use ionized gas (also called low-temperature and low-pressure plasma) on the coated surface. The kinetic energy of the gas particles increases and the temperature of the process can reach up to $500{ }^{\circ} \mathrm{C}$. This process can be used in an improved CVD method, which is also called the plasma-enhanced (plasma-activated (PA), or plasma-inducted (PI)) chemical vapor deposition (PE CVD, PA CVD, or PI CVD) method. During plasmochemical processes (e.g., based on $\mathrm{Ar}$ and $\mathrm{N}_{2}$ ) the gas mixture is ionized and kinetic energy is transmitted to the used precursors, for example, wolfram carbonyl [21-31], chromium carbonyl [23,26,28,30,32-35], and molybdenum carbonyl [21,29-31,36], which sublime in the reactor at low temperatures.

Importantly, Garner et al. [26] described the lawfulness of W, Cr, and Mo carbonyl decompositions, while Rezuchina et al. [28] studied the relation of saturated vapor pressures and sublimation temperatures of $\mathrm{W}, \mathrm{Cr}$, and Mo carbonyls. Additionally, Chellappa and Chandra [30] described data relating to the pressure of $\mathrm{W}, \mathrm{Cr}$, and Mo carbonyls. The production and decomposition of $\mathrm{Mo}(\mathrm{CO})_{6}$ and $\mathrm{W}(\mathrm{CO})_{6}$ were presented by Usoltsev et al. [31].

The properties of WC/C coatings deposited by using PE CVD methods have been widely studied [22-25,27], as well as the properties of the $\mathrm{Cr} / \mathrm{C}$ [33-35] and MoC/C [29] layers. To obtain a higher value of surface hardness and lower $\mathrm{COF}$ of WC/C thin coatings, $\mathrm{C}_{2} \mathrm{H}_{2}[23]$ and $\mathrm{N}_{2}[8,17,27]$ gases have been used during the deposition process.

In this study, based on our previous experiments [27], we focused on the microstructure, chemical composition, and selected useful properties of WC/C coatings deposited using an $\mathrm{N}_{2}-\mathrm{SiH}_{4}$ gas mixture and tested after annealing at various temperatures $(200,500$, and $800{ }^{\circ} \mathrm{C}$ ); the selected mechanical and tribological properties (i.e., hardness, Young's modulus, and the coefficient of friction) of the deposited WC/C coatings were analyzed. The obtained results are discussed and compared with the results of other studies published in the literature on this field.

\section{Materials and Methods}

\subsection{Sample Preparation}

For the deposition process of the WC/C coatings, two types of substrates were used, monocrystal of Si $(20 \times 15 \times 1 \mathrm{~mm}$, for evaluating thickness and structure $)$ and construction steel C45 (AISI 1045, for evaluating tribological tests). The chemical composition (wt.\%) of the steel substrate is as follows: $0.42 \div 0.50 \mathrm{C}, 0.40 \mathrm{Si}, 0.50 \div 0.80 \mathrm{Mn}, 0.40 \mathrm{Cr}, 0.10 \mathrm{Mo}$, $0.4 \mathrm{Ni}$, and $0.035 \mathrm{P}$, according to the Slovak Technical Standards (STN 412050) [27]. The steel samples were cut using wire electrical discharge machining from bars with diameters of 50 and $25 \mathrm{~mm}$ and machined to a thickness of $3.00 \pm 0.05 \mathrm{~mm}$. Furthermore, the substrates were case hardened in oil after being heated to $860{ }^{\circ} \mathrm{C}$, and subsequently annealed at $200{ }^{\circ} \mathrm{C}$. After thermal processing, the substrates were polished using diamond pastes with granularity equal to 15,9 , and $3 \mu \mathrm{m}$. Finally, the samples were polished using $1 \mu \mathrm{m}$ diamond paste to obtain surface roughness $\left(R_{a}\right)$ values of $12 \mathrm{~nm}$. In the next stage, the substrates were cleaned in acetone using an ultrasonic batch for $10 \mathrm{~min}$ and dried in air for $5 \mathrm{~min}$. Following this, the samples were inserted into a vacuum chamber and etched in $\mathrm{Ar}$ plasma at a pressure $2 \mathrm{~Pa}$, where bias of the holder was $\mathrm{U}_{\mathrm{b}} \approx-5 \mathrm{kV}$, current density was $1 \mathrm{~mA} \cdot \mathrm{cm}^{-2}$, and the time was $15 \mathrm{~min}$ [27]. In addition, an Ar flow of $65 \mathrm{~cm}^{3} \cdot \mathrm{min}^{-1}$ in the vacuum chamber was applied.

\subsection{Coating Deposition and Annealing}

The coating was deposited by adding $\mathrm{Ar}$ (as the working gas) in the $\mathrm{N}_{2}-\mathrm{SiH}_{4}$ gas mixture, where the content of $\mathrm{SiH}_{4}$ (silane) was $1.5 \%$. Table 1 summarizes the technological 
parameters of the deposition process (which lasted for $2 \mathrm{~h}$ ) and the selected mechanical properties of the obtained coating before annealing.

Table 1. The technological parameters of the WC/C coating deposition using the PE CVD method using hexacarbonyl of $\mathrm{W}$ as the precursor and the selected mechanical properties of the obtained coating before annealing.

\begin{tabular}{ccccccc}
\hline $\begin{array}{c}\text { Type of } \\
\text { Coating }\end{array}$ & $\begin{array}{c}\text { Gas } \\
\text { Mixture }\end{array}$ & $\begin{array}{c}\text { Total } \\
\text { Pressure } \\
(\mathbf{P a})\end{array}$ & $\begin{array}{c}\text { Gas } \\
\text { Pressure } \\
\mathbf{( P a})\end{array}$ & $\begin{array}{c}\mathrm{H}_{\mathrm{IT}} \\
(\mathbf{G P a})\end{array}$ & $\begin{array}{c}\mathbf{E}_{I T} \\
(\mathbf{G P a})\end{array}$ & $\begin{array}{c}\text { COF } \\
(-)\end{array}$ \\
\hline $\mathrm{WC}$ & $\mathrm{N}_{2}-\mathrm{SiH}_{4}$ & 4.0 & 2.0 & $18.7 \pm 4.3$ & $220 \pm 17$ & 0.35 \\
\hline
\end{tabular}

The WC/C coatings were deposited in a ZIP 12 apparatus (NTC New Technology Centre, Košice, SK, Slovakia) with a sublimation chamber (Figure 1) using the PE CVD method by applying direct-current electric voltage [27].

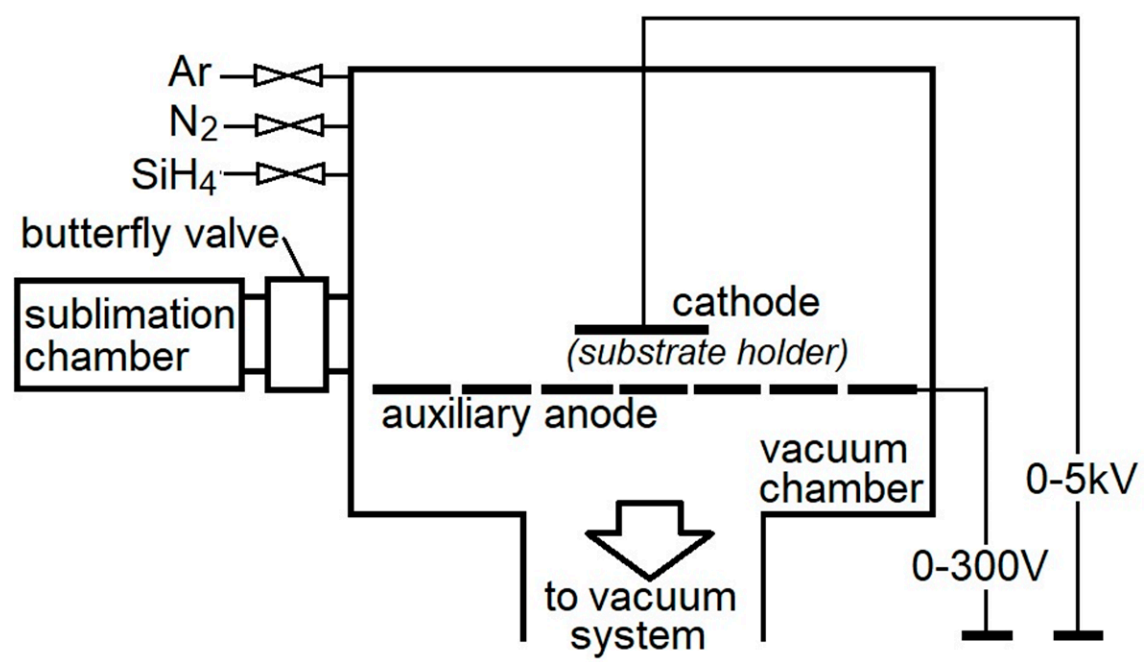

Figure 1. Scheme of the PE CVD equipment used during coating deposition, ZIP 12 type with sublimation chamber.

The substrates were placed on the cathode (substrate holder), where the maximum temperature of the deposition was controlled using Kapton tape (made from polyimide with a silicone sticking surface on one side). During the experiments, the crucible with the precursor was put into the sublimation chamber and closed using a butterfly valve between the sublimation chamber and the vacuum chamber. The cleaning procedure was performed under a pressure of $10^{-3} \mathrm{~Pa}$ using $\mathrm{Ar}$ (purity of 99.999\%) as the working gas. In the next stage, during the $\mathrm{WC} / \mathrm{C}$ coating deposition, the $\mathrm{W}(\mathrm{CO})_{6}$ (hexacarbonyl of $\mathrm{W}$ ) was used.

According to [29], during the coating deposition process, the $\mathrm{W}(\mathrm{CO})_{6}$ decomposes into $\mathrm{W}+6 \mathrm{CO}$, and then carbon monoxide is decomposed according to the Boudouard reaction $2 \mathrm{CO} \rightarrow \mathrm{C}+\mathrm{CO}_{2}$. These reactions occur simultaneously in the plasma and on the substrate.

Carbon created in this manner reacts with wolfram and, as a result, creates wolfram carbide (tungsten carbide, WC). Then, tungsten carbide is deposited onto the substrate with the influence of bias on the substrate (cathode).

Annealing of the WC/C coated substrates was carried out in an electric furnace at temperatures of 200,500 and $800{ }^{\circ} \mathrm{C}$, without a protective atmosphere. The duration of the annealing at the mentioned temperatures was $1 \mathrm{~h}$. After heating, the substrates were left to cool down. 


\subsection{Nanohardness and Young's Modulus}

After the deposition on steel substrates, selected mechanical properties of the WC/C coatings (specifically, hardness $\left(\mathrm{H}_{\mathrm{IT}}\right)$, and indentation ( $\left.\mathrm{E}_{\mathrm{IT}}\right)$ modulus) were measured using the instrumental indentation method (Nanoindenter NHT, CSM Instruments, Basel, Switzerland). The measurements were provided using sinus mode with an amplitude equal to $1 \mathrm{mN}$, applied load of 20-60 mN, and frequency of $15 \mathrm{~Hz}$. The values of indentation hardness and indentation modulus were calculated as an average of maximal values of indentation curves.

\subsection{Coefficient of Friction}

The COF measurements of the WC/C coatings prepared on the metal substrates were performed using a ball-on-disc method on a HTT tribometer (CSM Instruments, Basel, Switzerland). The following parameters were used for the tests: unencumbered strength, $0.5 \mathrm{~N}$; temperature, $21^{\circ} \mathrm{C}$; without a protective atmosphere, in the air; the counterpart (a steel ball) was made using $100 \mathrm{Cr} 6$ steel with a diameter of $6 \mathrm{~mm}$, a velocity of the balls' movements of $10 \mathrm{~cm} / \mathrm{s}$, and path length of $50 \mathrm{~m}$. The coefficient of friction was continuously measured in the course of every test as a function of time (in some cases as a function of the number of rotations) of the substrate and path length.

\subsection{SEM, AFM, and XPS Analyses}

The surface morphology of the evaluated coatings and their microstructures were observed using an electron microscope JEOL JSM 7000F (Tokyo, Japan).

The topography of the coated surface was measured by using an atomic force microscope (AFM) Dimension Icon, Veeco (Plainview, NY, USA).

The thicknesses of the coatings were evaluated using an electron microscope JEOL JSM 7000F by observing a transversal fracture of the WC/C coatings deposited on the Si substrates.

The chemical composition and selected atomic groups of the tested structures were observed using X-ray photoelectron spectroscopy (XPS). The XPS was performed on an instrument SPECS (SPECS GmbH, Berlin, Germany) equipped with a PHOIBOS 100 SCD and a non-monochromatic $\mathrm{X}$-ray source. The survey surface spectra of samples were measured at $70 \mathrm{eV}$ transition energy and core spectra at $30 \mathrm{eV}$, at room temperature. The spectra were all obtained at a basic pressure of $1 \times 10^{-8}$ mbar with $\mathrm{MgK} \alpha$ excitation at $10 \mathrm{kV}(200 \mathrm{~W})$. and the data analyses were performed using SpecsLab2 CasaXPS software (Casa Software Ltd., Teignmouth, UK). A Shirley and Tougaard type of baseline was used for all peak fits.

\section{Results and Discussion}

\subsection{Thickness, Morphology, and Chemical Composition}

Figures 2 and 3a, d show the AFM and SEM images of deposited WC/C coating characterized by a nanocolumnar structure. The thickness of the deposited coating was $0.75 \pm 0.05 \mu \mathrm{m}$ (Figure 3a). After annealing at a temperature of $500{ }^{\circ} \mathrm{C}$, the beginning of the coating degradation process can be observed, Figure $3 b$,e. The diameter of grains increased and, in places marked with arrows, column structures and the presence of globulites with a size up to $200 \mathrm{~nm}$ are visible, which point toward signs of coating degradation caused by swelling. Swelling is caused by the reaction between $C$ within the coating and oxygen from the atmosphere in an environment with higher temperatures. Next, $\mathrm{CO}_{2}$ is created, which swells within the coating. The outcome is a degraded coating in the whole cross-section, such as that shown by Lofaj F. and Kaganowskyy Yu.S. [37]. On the other hand, it can appear within the whole cross-section, but in small volumes (Figure 3c). As a result of annealing at $800^{\circ} \mathrm{C}$ (Figure 3f) and swelling, empty spaces with varying sizes ranging from 0.1 to $0.5 \mu \mathrm{m}$ (see arrows) are created. Despite this, the degradation of the WC/C coating deposited with the $\mathrm{N}_{2}-\mathrm{SiH}_{4}$-Ar gas mixture is significantly lower as compared with other study results [8,17], where massive degradation of WC/C coatings as a result of swelling 
alongside the whole cross-section have occurred, such as that shown by Lofaj F. and Kaganowskyy Yu.S. [37]. This indicates that the significant increase in the refractoriness of the WC/C coatings at the mentioned temperatures is the result of adding $1.5 \% \mathrm{SiH}_{4}$ (silane) to $\mathrm{N}_{2}$ during the PE CVD process as compared with the WC/C coatings deposited by applying the $\mathrm{N}_{2}-\mathrm{SiH}_{4}$ gas mixture using DCMS [8] and RFMS [17] methods. The thickness of the coating after annealing remained in the range of $0.75 \pm 0.05 \mu \mathrm{m}$ (Figure $3 \mathrm{c}, \mathrm{e}$ ).

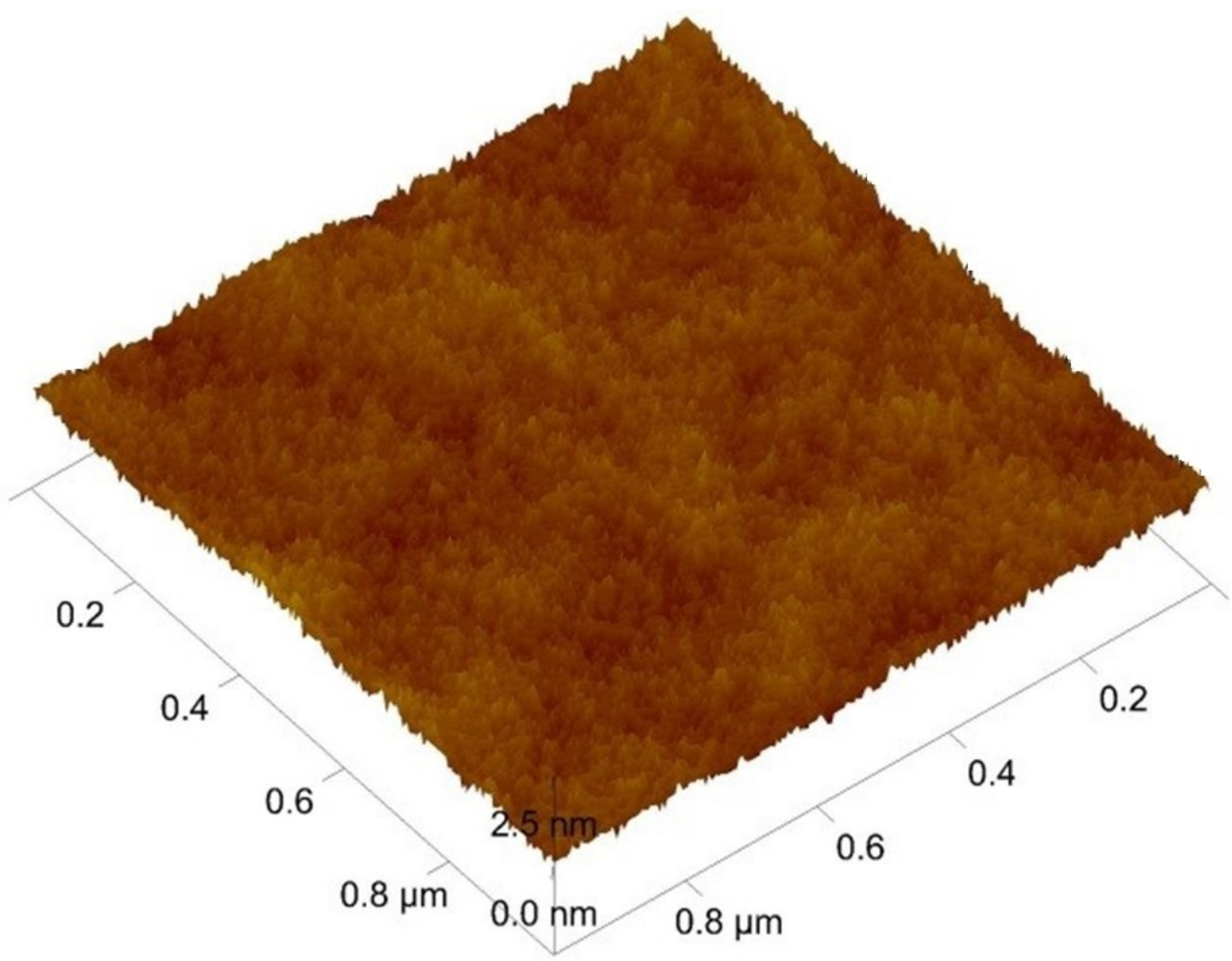

Figure 2. The AFM image (3D) of the unannealed WC/C coating.

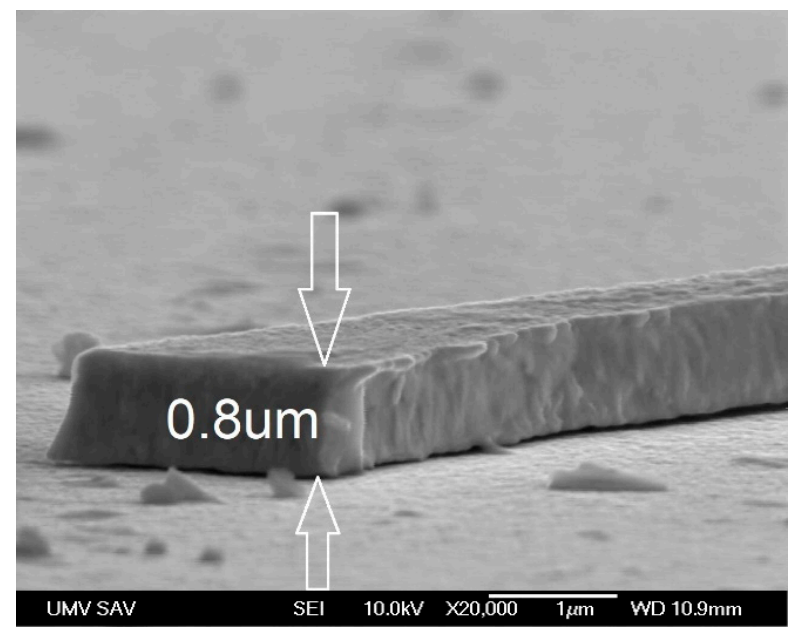

(a)

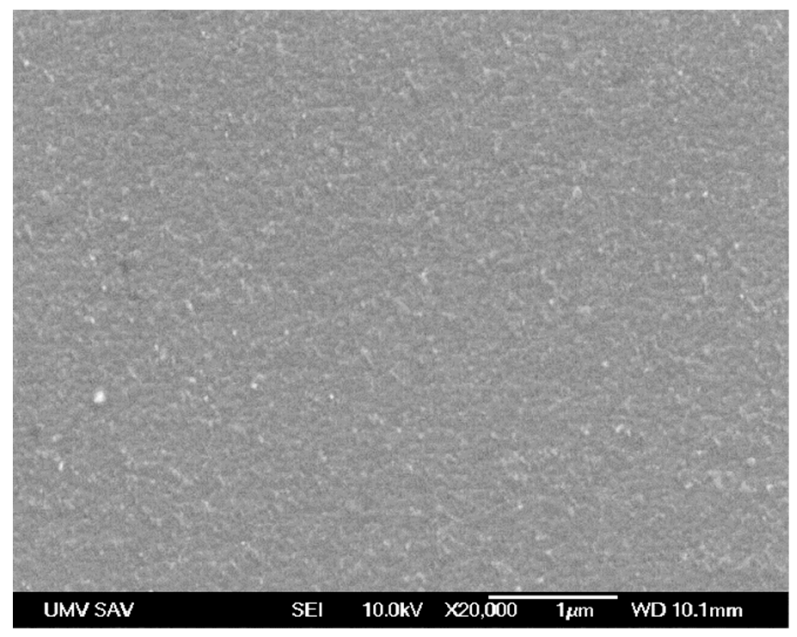

(b)

Figure 3. Cont. 


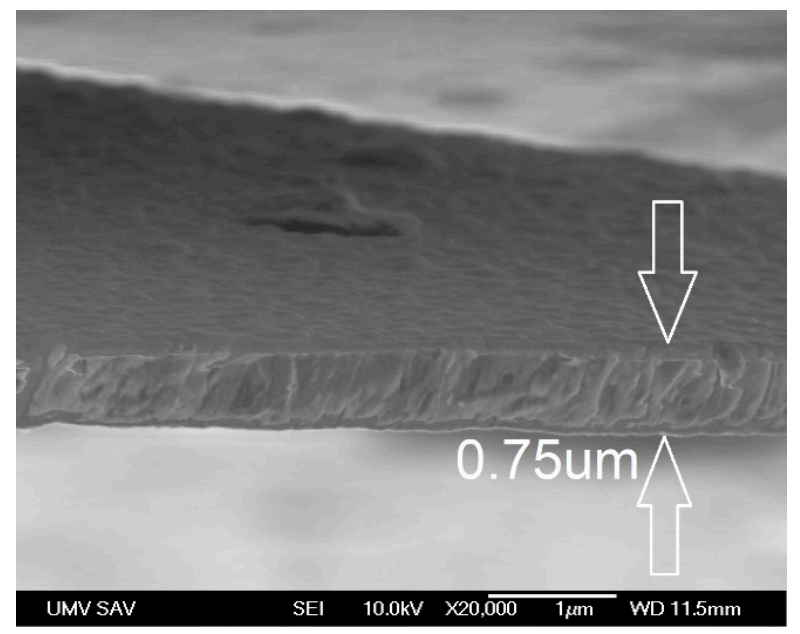

(c)

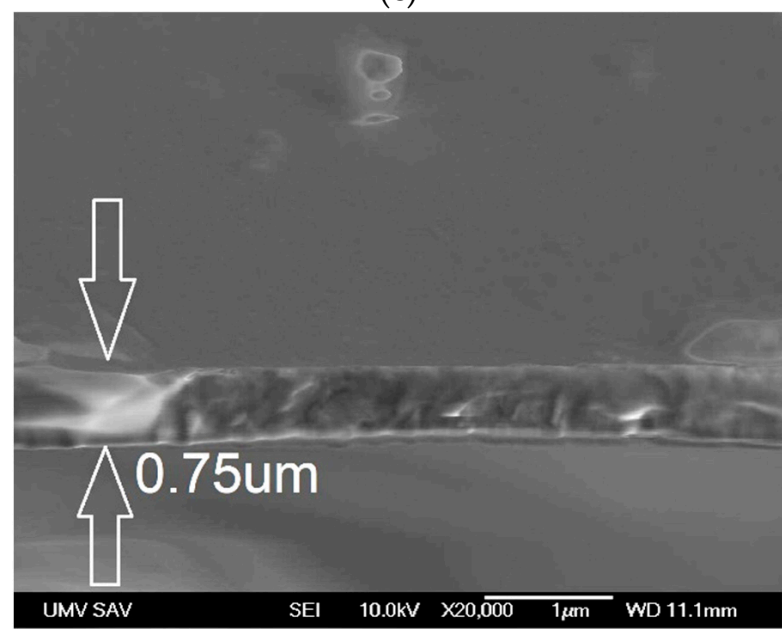

(e)

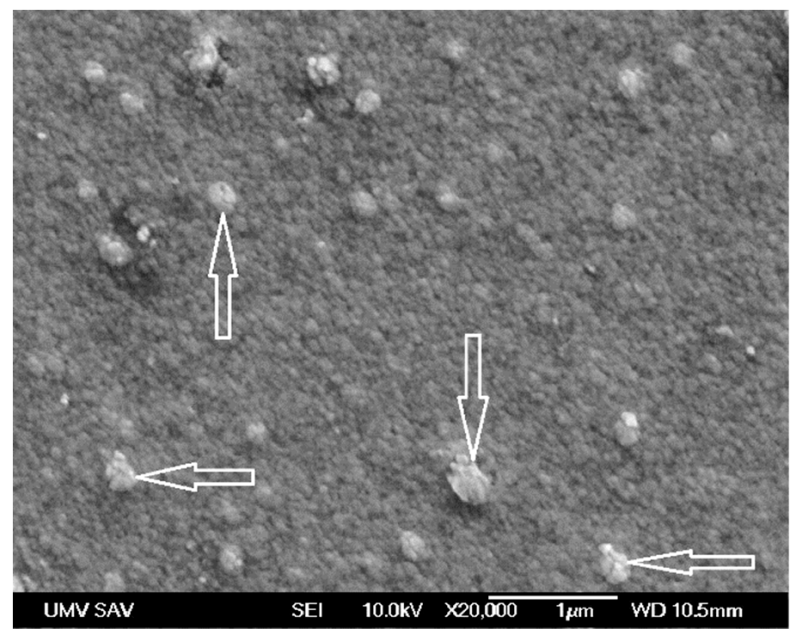

(d)

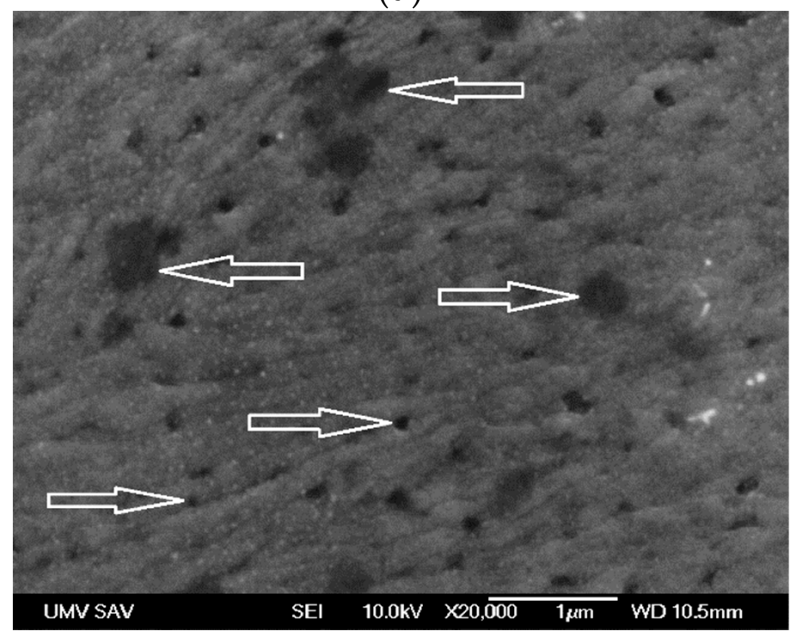

(f)

Figure 3. SEM images of the cross-sectional (left) and surface morphology (right) of WC/C coatings: (a,d) unannealed; (b,e) after annealing at $500^{\circ} \mathrm{C}$; (c,f) after annealing at $800^{\circ} \mathrm{C}$.

The most common chemical bonds in amorphous and nanocrystalline carbon films are $\mathrm{sp}^{3}$ and $\mathrm{sp}^{2}$ hybridizations. In the $\mathrm{sp}^{3}$ configuration, a carbon atom forms four $\mathrm{sp}^{3}$ orbitals making a strong $\sigma$ bond to the adjacent atom. In the $\mathrm{sp}^{2}$ configuration, a carbon atom forms three $\mathrm{sp}^{2}$ orbitals forming three $\sigma$ bonds and the remaining $p$ orbital forms a $\pi$ bond. The $\pi$ orbital geometrically lies normal to the $\sigma$ bond plane and is the weaker bond, and therefore it is closer to the Fermi level. The three $\sigma$ bonds and $\pi$ bond usually constitute a ring plane in $\mathrm{sp}^{2}$ clusters. An XPS analysis is a very sensitive method that can be used to identify and determine the concentration of elements within the escape depth of the photoelectrons in the near surface region. Because it can reveal the binding energy of the carbon atoms and discern the hybrid $\mathrm{sp}^{3}$ and $\mathrm{sp}^{2}$ bonds, it is a very powerful method for evaluating the structure of carbon films without causing excessive damage to the materials [38]. The XPS analysis evaluates the emitted electrons from the surface, and from the emitted electrons, we are able to characterize a binding energy which is typical for each element.

The XPS spectrum of the WC/C deposited unannealed coating (Figure 4a) shows the presence of $\mathrm{C} 1 \mathrm{~s} 82.2$ at.\%, $\mathrm{N}$ 1s 2.9 at.\%, Si 2 p 2.9 at.\%, and tungsten 8.0 at.\%.

In addition, the obtained results (Figure $4 \mathrm{~b}$ ) show the presence of hard WC and diamond phase (3.4 at.\%), graphite phase of C (66.0 at.\%), and phase of C-O (30.6 at.\%). The high-resolution spectrum of $\mathrm{N} 1 \mathrm{~s}$ nitrogen (Figure 4c) shows the presence of hard WC-N (65.4 at.\%) and nitrogen oxide (34.6 at.\%). The spectrum of silicon Si 2p contains two peaks (Figure $4 \mathrm{~d}$ ), and peak with a value of $99.72 \mathrm{eV}(11.0$ at.\%), which is characteristic for the $\mathrm{SiC}$ 
phase and confirms the binding of silicon in a thin layer. A peak of $103.12 \mathrm{eV}$ (89.0 at.\%) is characteristic for the silicon nitride phase. The high-resolution spectrum of $\mathrm{W} 4 \mathrm{f}$ tungsten is divided into four peaks (Figure 4e), i.e., peaks with values of $38.85 \mathrm{eV}$ (18.4 at.\%) and $36.59 \mathrm{eV}(48.4$ at.\%) are characteristic for nitrogen-bound tungsten. In addition, the tungsten carbide compound is confirmed by peaks of $33.99 \mathrm{eV}$ and $32.16 \mathrm{eV}(20.8$ at.\% and 12.5 at.\%). These results are in good agreement with results for $\mathrm{C}$ deconvolution [39], $\mathrm{N}$ convolution [40], and W convolution [41].

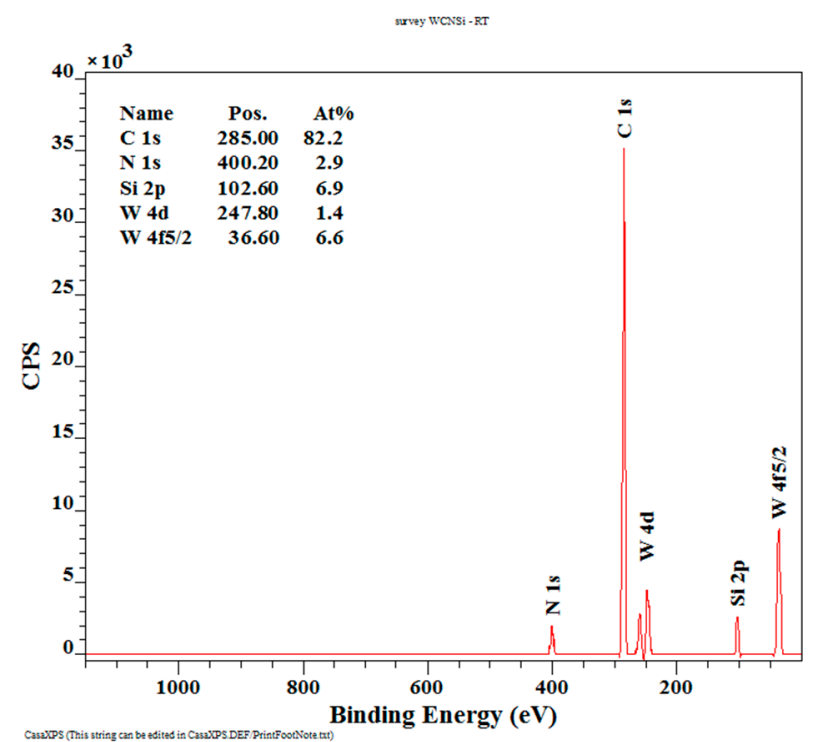

(a)

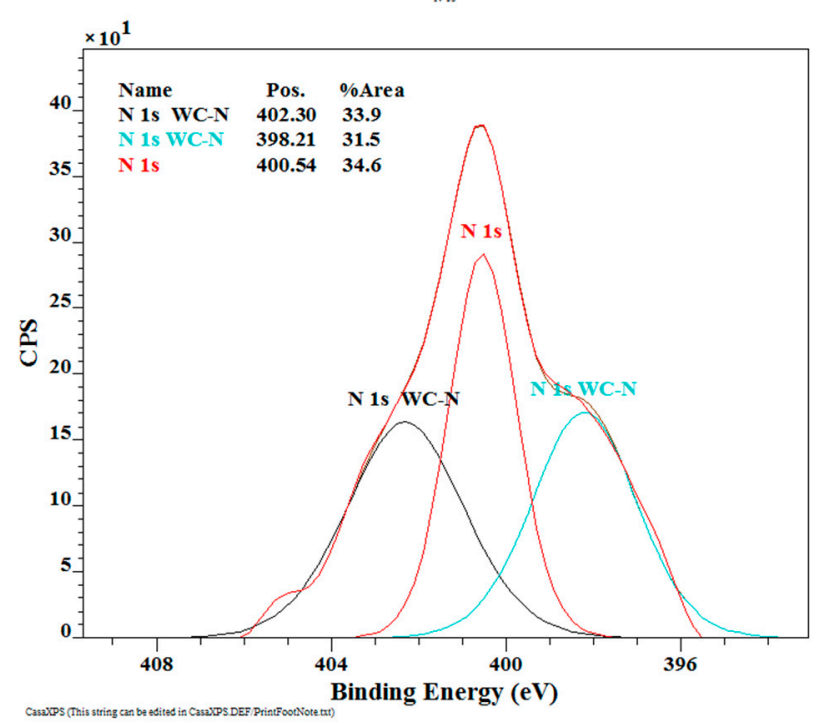

(c)

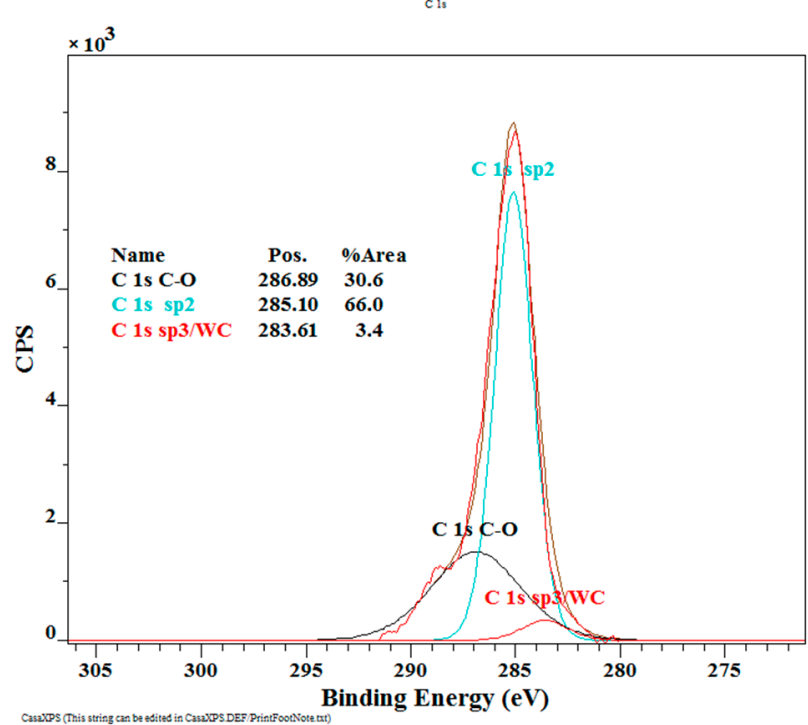

(b)

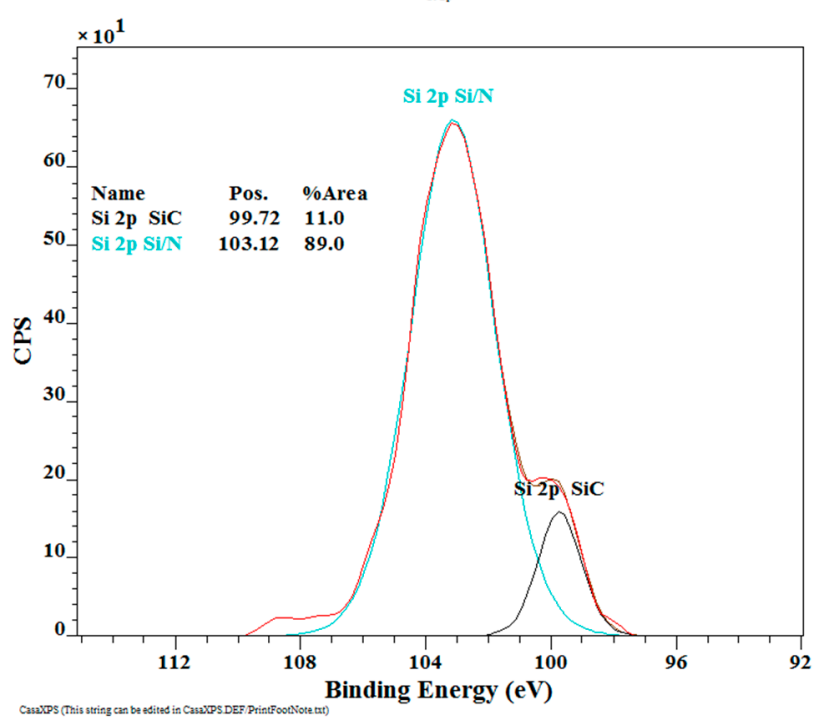

(d)

Figure 4. Cont. 


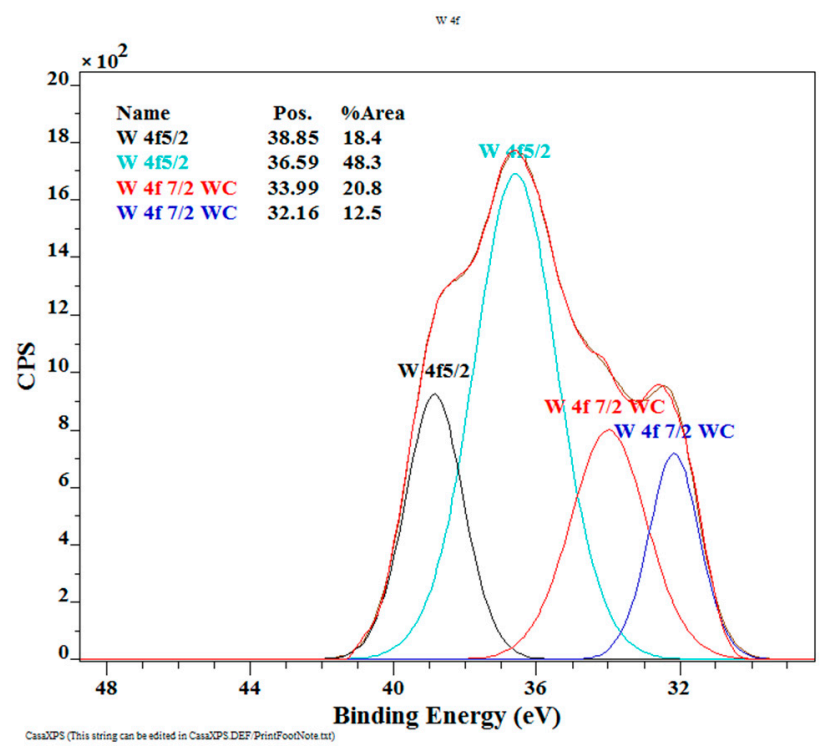

(e)

Figure 4. The XPS spectra of the deposited WC/C coatings: (a) Chemical composition (at.\%); (b-e) chemical bonds of selected elements.

This is beneficial for the creation of chemical compounds, such as $\mathrm{WSi}_{2}, \mathrm{SiC}_{1} \mathrm{SiO}_{2}$, and $\mathrm{Si}_{3} \mathrm{~N}_{4}$. These phases in the obtained structure during deposition and after annealing caused an increase in the refractoriness properties of the WC/C coating. Changes in the structure of the coating related to chemical reactions took place during the process of annealing at $500{ }^{\circ} \mathrm{C}$ without the protective atmosphere.

As shown in Figure $5 a$, the surface spectra of the WC/C coatings after annealing at $500{ }^{\circ} \mathrm{C}$ show the presence of oxygen, carbon, nitrogen, silicon, and tungsten, i.e., $\mathrm{O} 1 \mathrm{~s}$ 15.6 at.\%, C 70.2 at.\%, N 1s 1.9 at.\%, Si 2p 10.5 at.\%, and W 1.9 at.\%, respectively.

The high-resolution spectrum of $\mathrm{C} 1 \mathrm{~s}$ carbon (Figure $5 \mathrm{~b}$ ) can be decomposed into three peaks, a peak of $286.29 \mathrm{eV}$ (42.3 at.\%), which is characteristic for the carbon in the $\mathrm{C}=\mathrm{O}$ bond; the carbon bonded with oxygen from the air, a peak of $284.96 \mathrm{eV}$ is attributed to the C-O bond (51.3 at.\%); and the peak at $283.61 \mathrm{eV}$ is typical for $\mathrm{sp}^{3}$ hybridization, which is characteristic for the diamond phase and the tungsten carbide compound (6.4 at.\%). The presence of nitrogen (Figure $5 \mathrm{c}$ ) on the surface of the coating confirms the high-resolution $\mathrm{N}$ 1s spectrum. From the given spectrum, we can confirm the bonding of the nitrogen, carbon, and tungsten in a thin layer. The value of $400.00 \mathrm{eV}$ is attributed with nitrogen oxide. The high-resolution spectrum of silicon Si $2 p$ (Figure $5 d$ ) contains two peaks. A line with a value of $99.72 \mathrm{eV}(8.8$ at.\%) is characteristic for the $\mathrm{SiC}$ compound, which confirms the binding of silicon in a thin layer. A peak of $103.12 \mathrm{eV}$ (91.2 at.\%) is characteristic for silicon oxide.

The high-resolution spectrum of tungsten $\mathrm{W} 4 \mathrm{f}$ (Figure 5e) is divided into four peaks, i.e., values of $3572 \mathrm{eV}$ (50.7 at.\%) and $3783 \mathrm{eV}$ (42.4 at.\%) are characteristic for oxygen-bound tungsten. The tungsten carbide compound is confirmed by a peak at the value of $32.64 \mathrm{eV}$ (3.7 at.\%) and at the value of $30.65 \mathrm{eV}$ (3.2 at.\%).

As is shown in Figure 6 a (after annealing at $800^{\circ} \mathrm{C}$ ), the surface spectra of the WC/C coatings show the presence of O 1s 15.6 at.\%, C 1 s 65.9 at. $\%, \mathrm{~N} 1$ s 3.2 at.\%, Si 2p 7.5 at.\%, and tungsten 7.8 at. $\%$. 


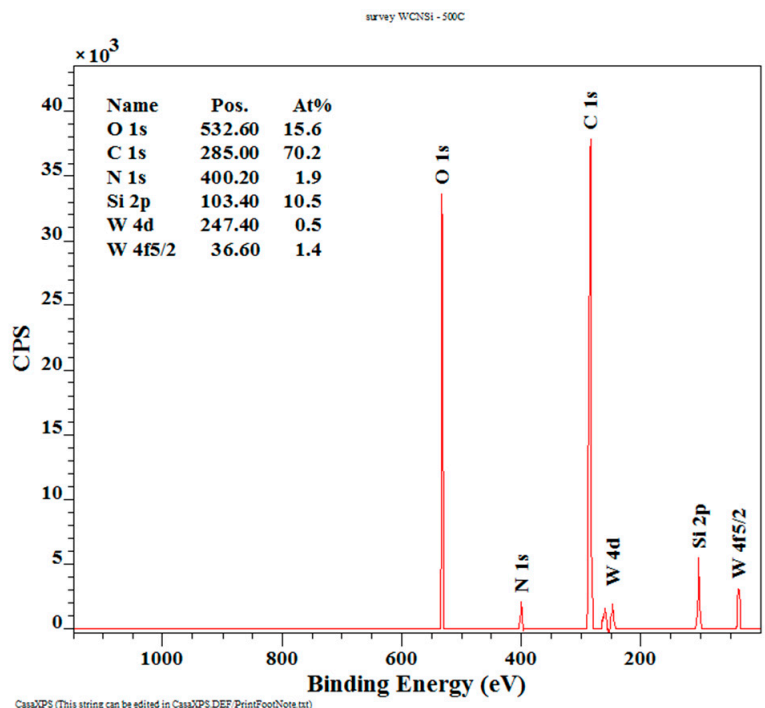

(a)

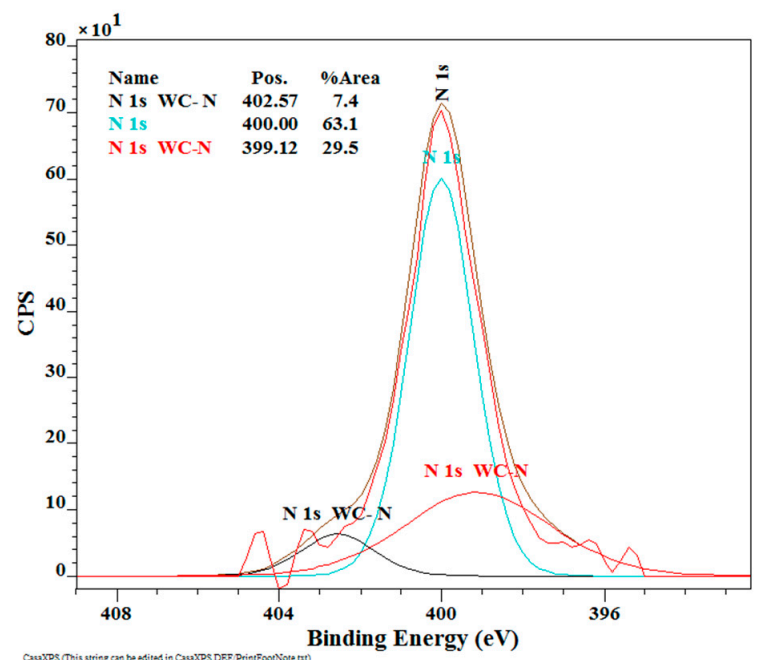

(c)

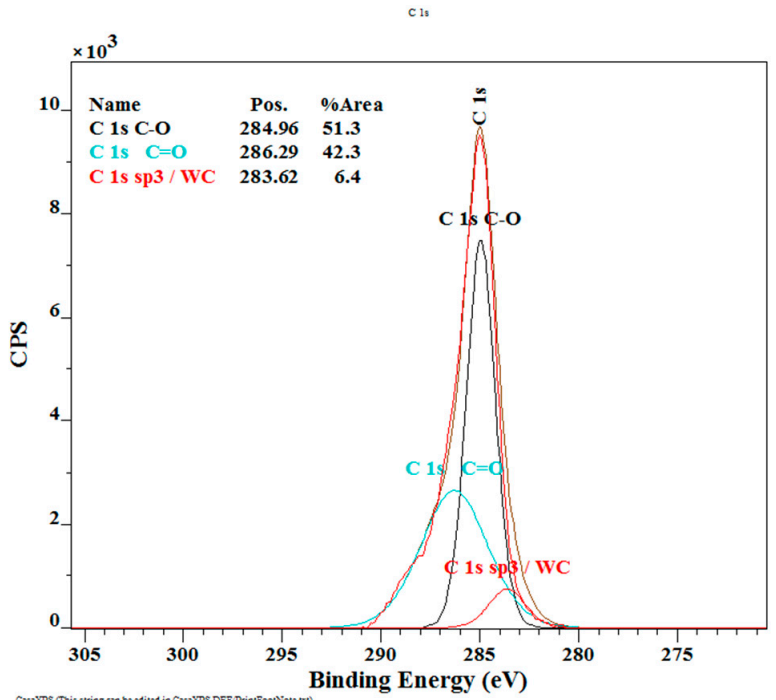

(b)

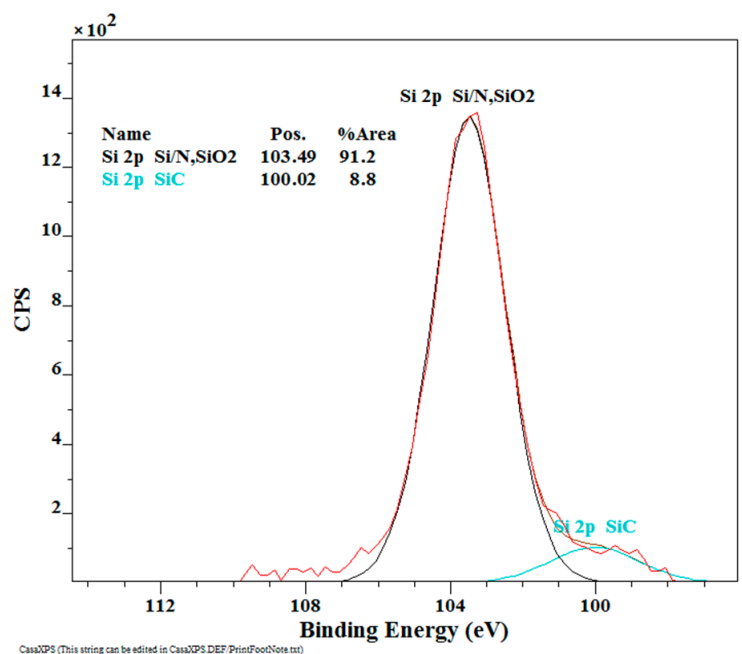

(d)

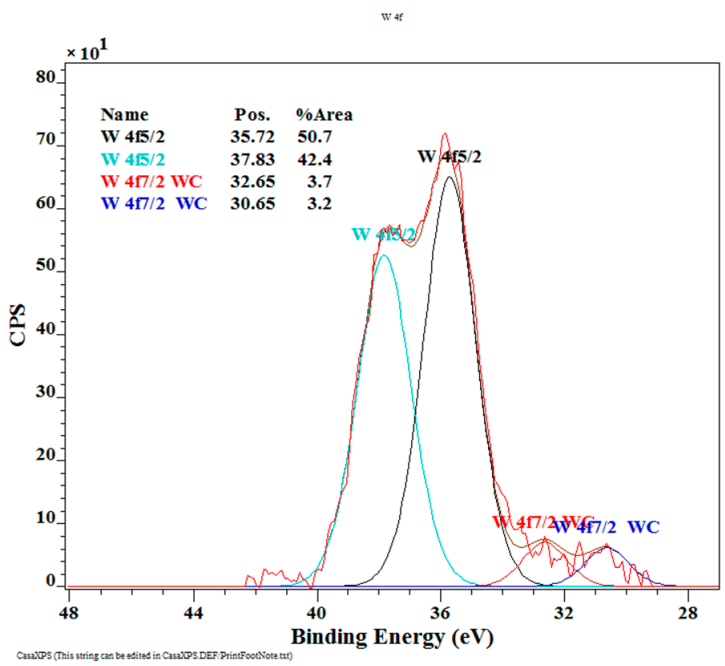

(e)

Figure 5. The XPS surface results of the WC/C coating annealed at $500{ }^{\circ} \mathrm{C}$ (at.\%): (a) chemical composition; (b) chemical bonds $\mathrm{C}$; (c) chemical bonds $\mathrm{N}$; (d) chemical bonds $\mathrm{Si}$; (e) chemical bonds $\mathrm{W}$. 


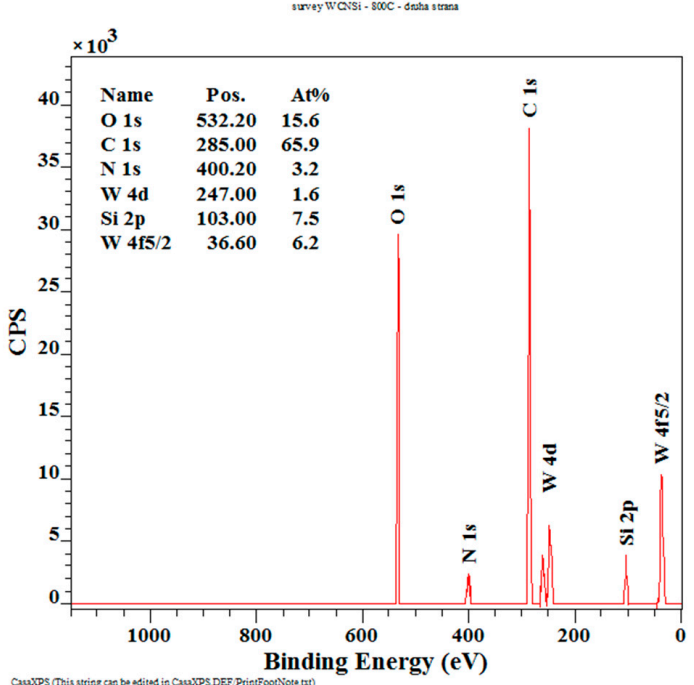

(a)

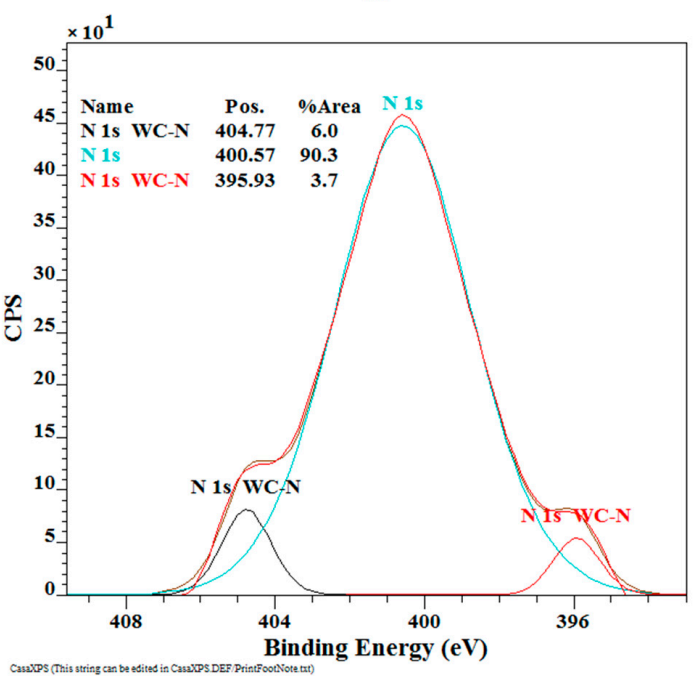

(c)

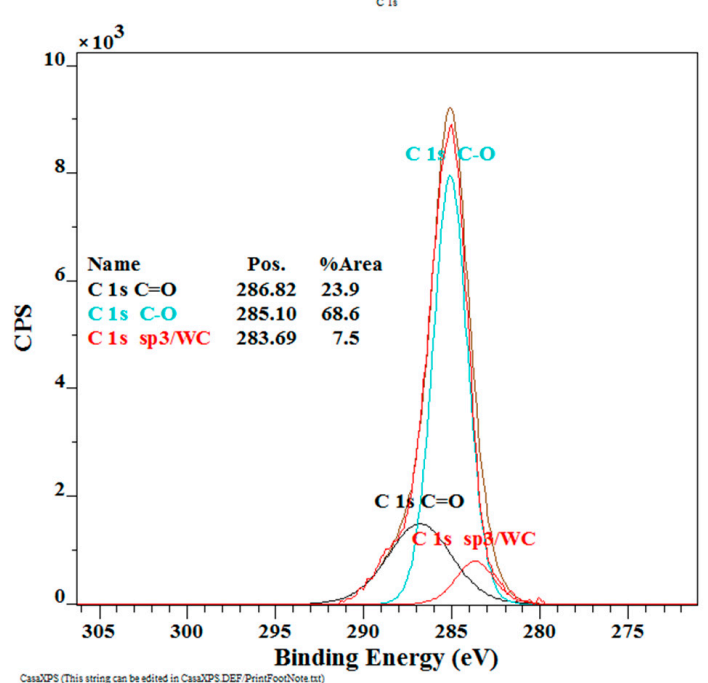

(b)

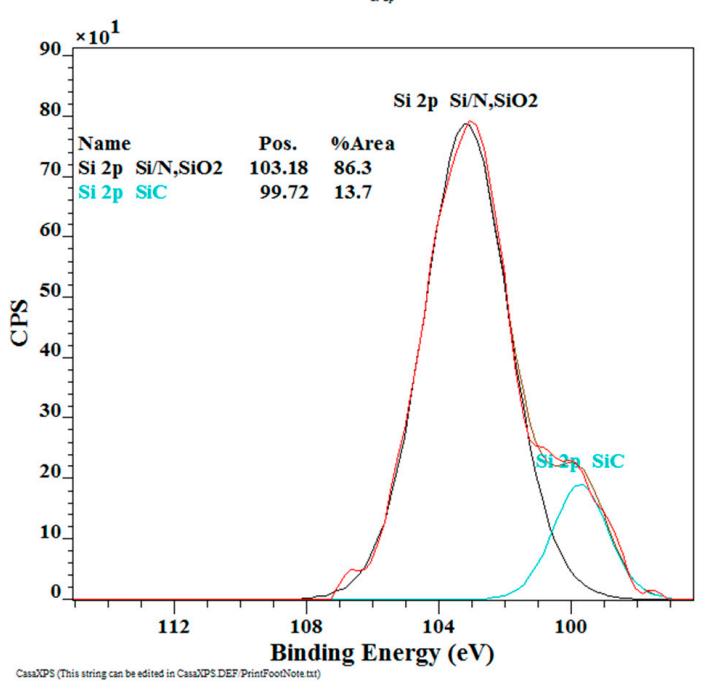

(d)

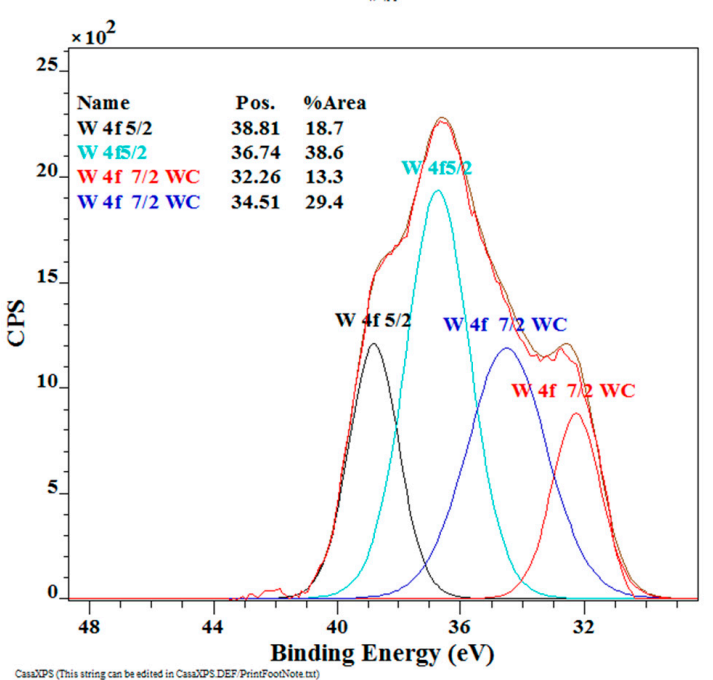

(e)

Figure 6. The XPS results from the surface of the WC/C annealed coating at $800{ }^{\circ} \mathrm{C}$ (at.\%): (a) Chemical composition; (b) chemical bonds C; (c) chemical bonds N; (d) chemical bonds $\mathrm{Si}$; (e) chemical bonds W. 
The high-resolution spectrum of $\mathrm{C} 1 \mathrm{~s}$ carbon (Figure $6 \mathrm{~b}$ ) can be decomposed into three peaks, a peak of $286.82 \mathrm{eV}$ (23.9 at.\%), which is characteristic for the carbon in the $\mathrm{C}=\mathrm{O}$ bond; the carbon bonded with oxygen from the air, a peak of $285.1 \mathrm{eV}$-the given peak is attributed to the $\mathrm{C}-\mathrm{O}$ bond (68.6 at.\%); and the peak at $283.69 \mathrm{eV}$ is typical for $\mathrm{sp}^{3}$ hybridization, which is characteristic for the diamond phase and the tungsten carbide compound (7.5 at.\%).

The presence of nitrogen in the tested sample confirms the high-resolution $\mathrm{N} 1 \mathrm{~s}$ spectrum (Figure 6c), the peak at the value of $400.57 \mathrm{eV}$ (90.3 at.\%) belongs to nitrogen oxide. The high-resolution spectrum of silicon Si $2 p$ (Figure $6 \mathrm{~d}$ ) contains two peaks, with a value of $99.72 \mathrm{eV}$ (13.7 at.\%) characteristic for the $\mathrm{SiC}$ phase. The peak of $103.18 \mathrm{eV}$ (86.3 at.\%) is characteristic for silicon oxide in the obtained structure.

The high-resolution spectrum of $\mathrm{W} 4 \mathrm{f}$ tungsten (Figure 6e) is divided into four peaks, with a value of $38.81 \mathrm{eV}(18.7$ at.\%) and with a value of $36.74 \mathrm{eV}$ (38.6 at.\%), which are characteristic for oxygen-bound tungsten. In addition, the tungsten carbide compound is confirmed by peaks of $32.26 \mathrm{eV}$ and $34.51 \mathrm{eV}$ (13.3 at.\% and 29.4 at.\%).

\subsection{Hardness and Young's Modulus}

Figure 7 shows a depth profile of the indentation hardness course of the tested WC/C coating deposited using the $\mathrm{N}_{2}-\mathrm{SiH}_{4}$-Ar gas mixture.

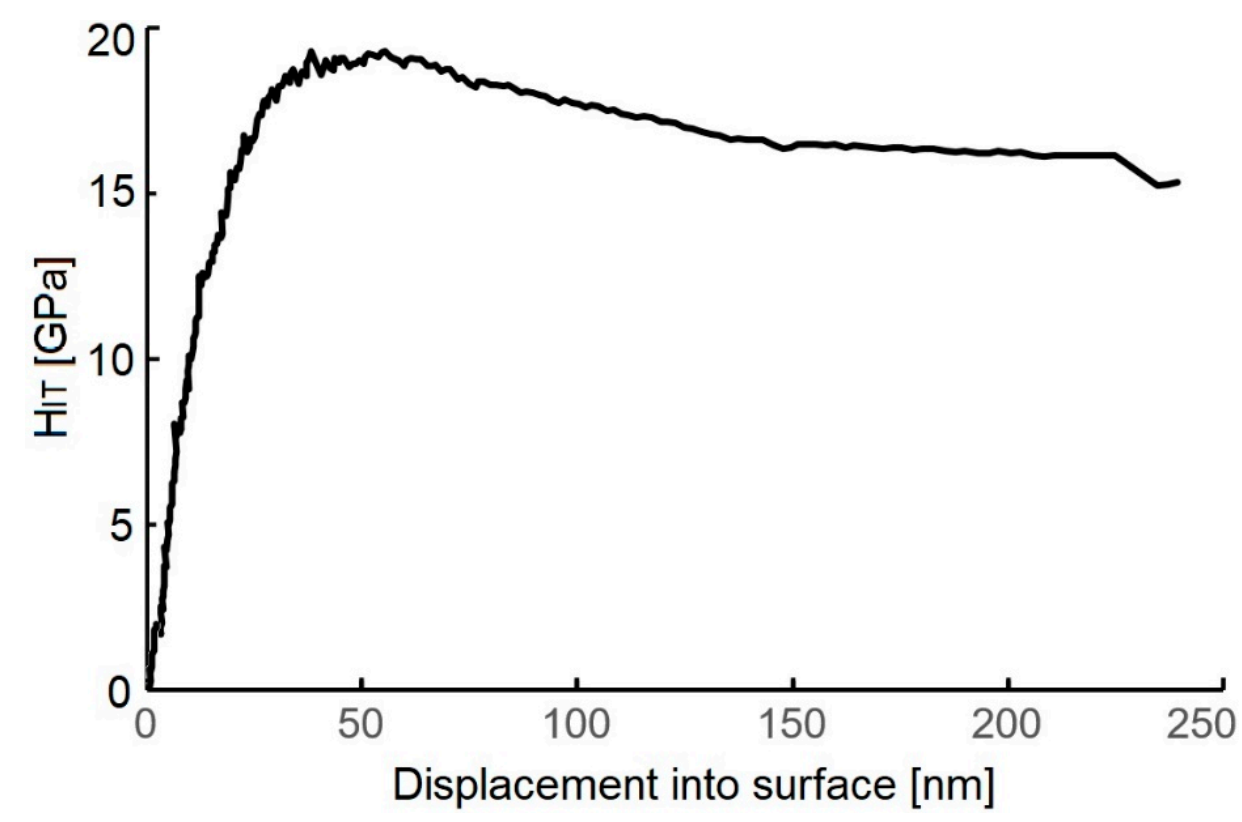

Figure 7. Depth profile of the $\mathrm{H}_{\mathrm{IT}}$ values of the tested WC/C coating.

The maximum $\mathrm{H}_{\text {IT }}$ value of the deposited coating is $18.7 \pm 4.3 \mathrm{GPa}$ as compared with that obtained by other studies, namely [8] (18.0 $\pm 3.1 \mathrm{GPa})$ and [17] $(22.1 \pm 2.5 \mathrm{GPa})$, where thin layers were obtained using the DCMS and RFMS techniques, respectively. Simultaneously, the hardness is 30\% lower as compared with the hardness of the WC/C coatings deposited using the PE CVD method with and without adding Ar in a gas mixture [27]. Young's modulus of the tested samples is $220 \pm 17 \mathrm{GPa}$ (Figure 8).

After annealing at $200{ }^{\circ} \mathrm{C}$, the $\mathrm{H}_{\mathrm{IT}}$ decreased to $12.5 \pm 2.3 \mathrm{GPa}$ (Figure 9). The hardness of the coating did not change after annealing the coated substrate at $500^{\circ} \mathrm{C}$. A slight increase in hardness to $15.0 \pm 2.7 \mathrm{GPa}$ can be spotted after annealing the coated substrate at $800{ }^{\circ} \mathrm{C}$, which is more than in the case of WC/C coating deposited using the PE CVD method with added $\operatorname{Ar}(12.0 \pm 0.8 \mathrm{GPa})$ and significantly more than in the case of added $\mathrm{N}_{2}$ gas $(3.0 \pm 0.2 \mathrm{GPa})[27]$. 


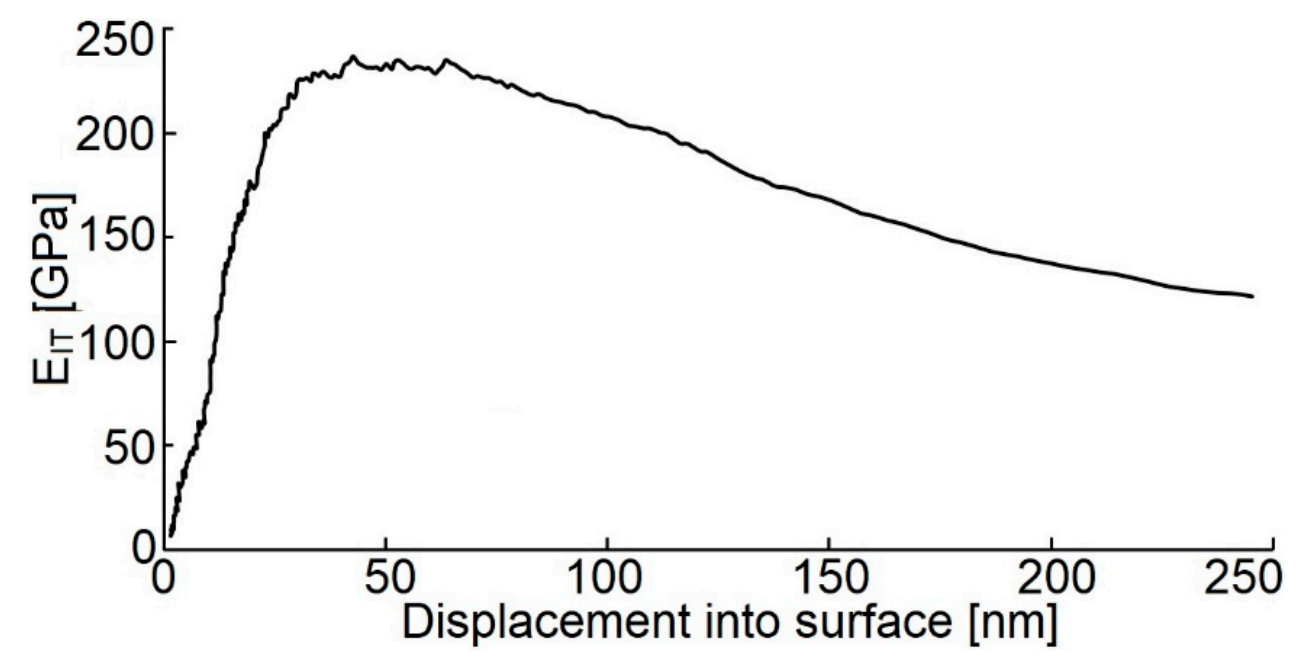

Figure 8. Depth profile of the $\mathrm{E}_{\mathrm{IT}}$ values of the tested WC/C coating.

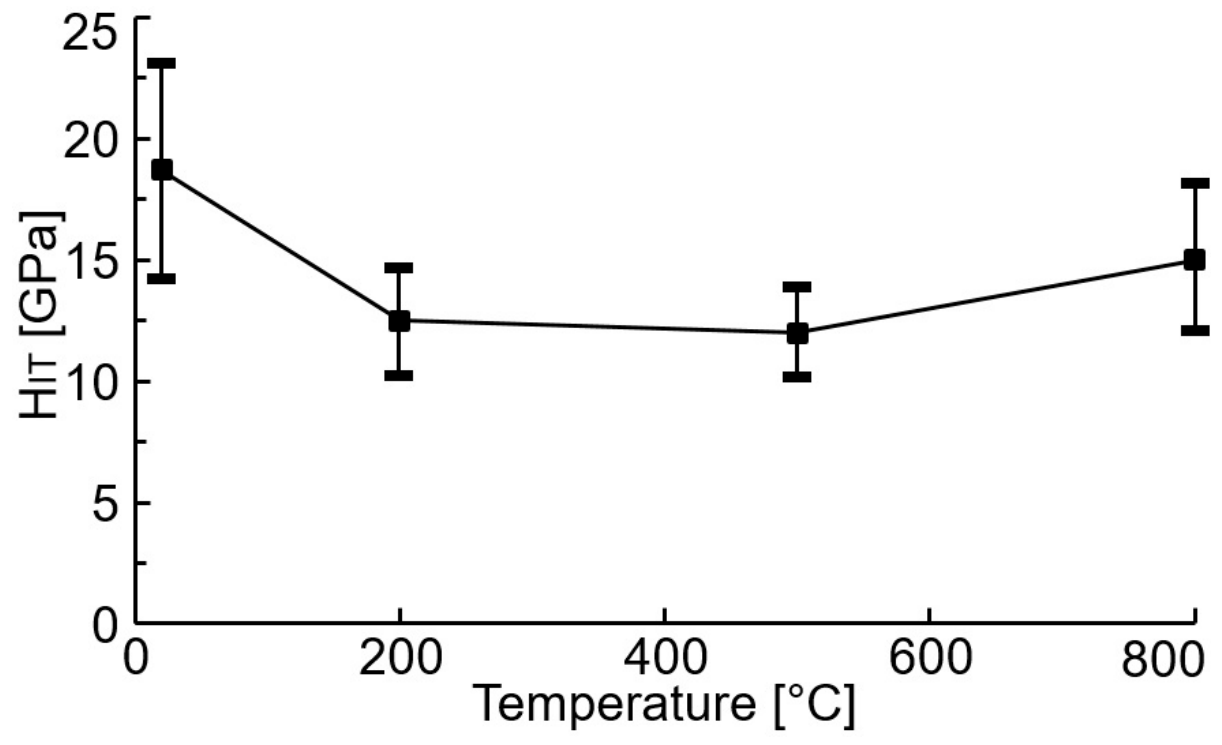

Figure 9. The $\mathrm{H}_{\mathrm{IT}}$ values vs. the annealing temperature of the tested $\mathrm{WC} / \mathrm{C}$ coatings.

The mentioned difference could be attributed to the presence of $\mathrm{WC}, \mathrm{WN}, \mathrm{W}_{2} \mathrm{~N}, \mathrm{SiC}$, and $\mathrm{SiN}$ which have been made in the process of deposition of the coating (Figure $4 \mathrm{~b}-\mathrm{e}$ ) or during annealing, especially at a temperature of $800^{\circ} \mathrm{C}$ (Figure $6 \mathrm{~b}-\mathrm{e}$ ). It can also be stated that the mentioned differences correspond with the degree of distraction of the coating (as compared with the results by [27]) after annealing at the mentioned temperature. As compared with the results by [27], the least disrupted coating was the one which was deposited in the $\mathrm{N}_{2}-\mathrm{SiH}_{4}$-Ar atmosphere (Figure $3 \mathrm{f}$ ).

\subsection{Coefficient of Friction}

Measures of the COF $(0.35 \pm 0.02$, Figure 10$)$ agree with other study results [8], where the achieved values of the COF of the WC/C coatings deposited with added $\mathrm{N}_{2}$ and $\mathrm{Ar}$ gas are equal to $0.58 \pm 0.03$ and. $0.77 \pm 0.03$, respectively.

If we compare the measured COF values of and the WC/C coatings deposited with the $\mathrm{N}_{2}-\mathrm{SiH}_{4}$ gas mixture using the DCMS $(0.28 \pm 0.03)$ [8] and RFMS $(0.23 \pm 0.02)$ [17] methods, it can be said that our measured value of COF increased by ca. $30 \%$. 


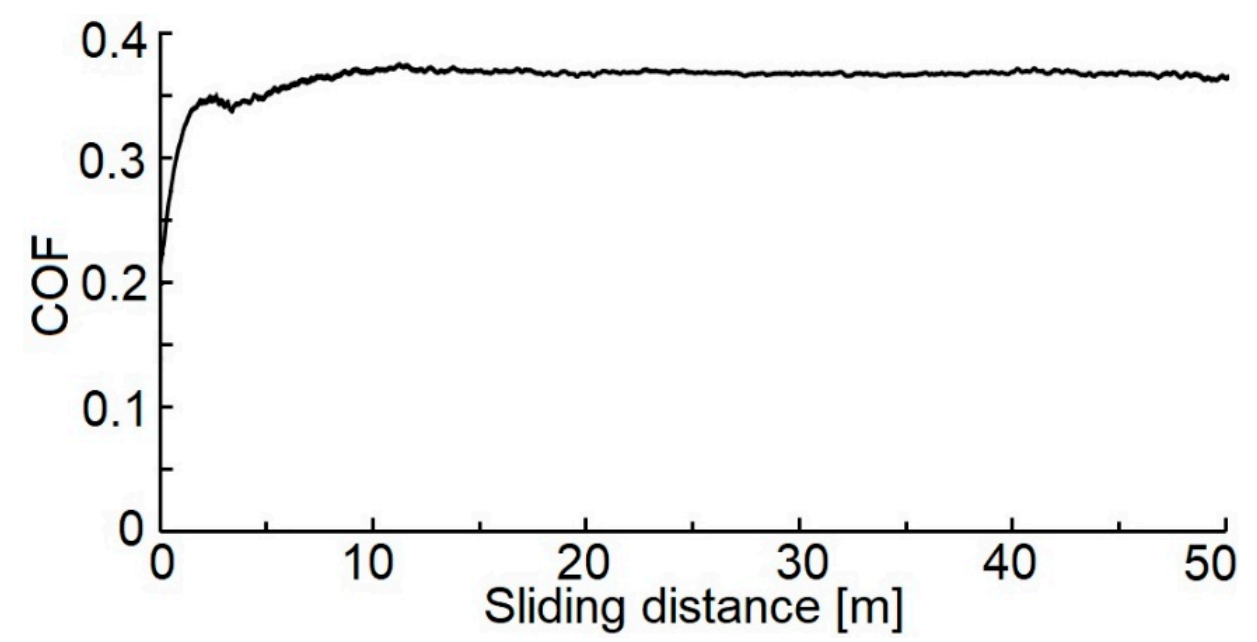

Figure 10. The COF values vs. the sliding distance of the tested WC/C coating.

In contrast, after the applied annealing process at a temperature of $200{ }^{\circ} \mathrm{C}$, the $\mathrm{COF}$ value increased slightly to $0.36 \pm 0.03$ (Figure 11).

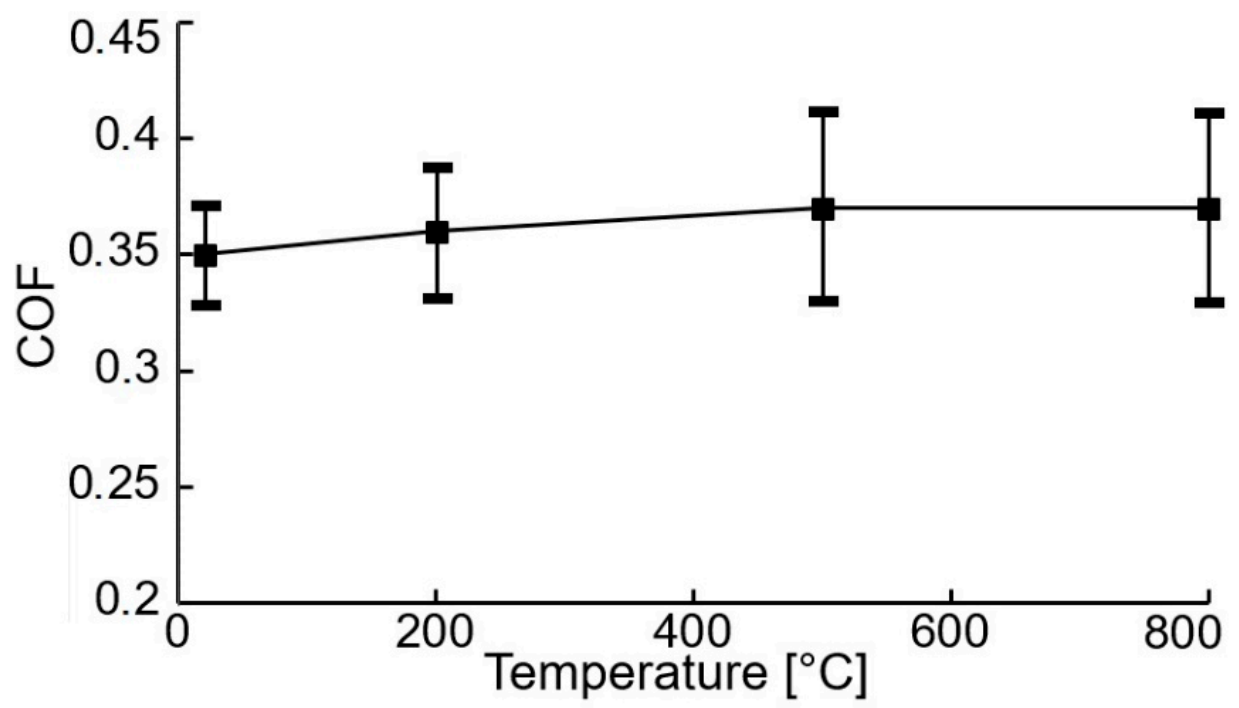

Figure 11. The COF values vs. the annealing temperature of the tested $\mathrm{WC} / \mathrm{C}$ coatings.

After annealing at $500{ }^{\circ} \mathrm{C}$ and $800{ }^{\circ} \mathrm{C}$, the value of the COF was equal to $0.37 \pm 0.40$. This value increased by ca. $30 \%$ as compared with other study results $(0.27 \pm 0.02$ [8] and $0.26 \pm 0.01$ ) [17] (annealing at a temperature of $500{ }^{\circ} \mathrm{C}$ ) and by ca. $35 \%$ as compared with $(0.22 \pm 0.01)$ [17] (annealing at a temperature of $\left.800{ }^{\circ} \mathrm{C}\right)$. It can be stated that the evaluated WC/C coatings deposited with the $\mathrm{N}_{2}-\mathrm{SiH}_{4}$ gas mixture have shown only an insignificant increase in the COF values after annealing at temperatures of 200, 500 and $800{ }^{\circ} \mathrm{C}$ (Figure 11$)$.

The presented differences in the COF values (for the $\mathrm{WC} / \mathrm{C}$ coating that has not been annealed) can be attributed to the amount of $C$ in the graphite phase, which acts as a dry lubricant and causes a decrease in the COF value. In addition, regarding high COF values, $C$ is present in harder particles, such as $W C$ and $W_{1-X}, W N$ and $W_{2} N$, and even SiC, which in small amounts can be created during the coating deposition and, especially, during the annealing process at high temperatures (in our case at $800^{\circ} \mathrm{C}$ ). The presence of these harder particles in the WC $/ \mathrm{C}$ coating causes an increase in the $\mathrm{H}_{\mathrm{IT}}$ value. If a significantly softer counterpart is used, relative to the evaluated surface of the WC/C coating, the presence of 
harder particles in the WC/C coatings can cause an increase in the COF, which is attributed to an increase in contact surface during the tribological test.

\section{Conclusions}

According to the results of the tested samples of deposited WC/C coatings (unannealed and annealed at various temperatures), it can be stated that:

i. The obtained WC/C coatings using the PE CVD method are characterized by the following measurements of evaluated properties: $\mathrm{H}_{\mathrm{IT}}=18.7 \pm 4.3 \mathrm{GPa}, \mathrm{E}_{\mathrm{IT}}=220 \pm 17 \mathrm{GPa}$, and $\mathrm{COF}=0.35 \pm 0.02$. In addition, higher values of hardness can be obtained by optimizing the technological process parameters.

ii. On the one hand, the annealing process causes a significant decrease in the $H_{I T}$ value, starting at $200{ }^{\circ} \mathrm{C}$. On the other hand, after annealing at 500 and $800{ }^{\circ} \mathrm{C}$, the hardness increases only insignificantly as compared with hardness after annealing at $200{ }^{\circ} \mathrm{C}$.

iii. After annealing without a protective atmosphere at $500{ }^{\circ} \mathrm{C}$, a slight coarsening of the granulate was spotted on the surface of the WC/C coating, creating bulgy particles with a diameter up to ca. $200 \mathrm{~nm}$.

iv. The annealing process at $800^{\circ} \mathrm{C}$ caused the creation of empty spaces in the coating with a diameter up to ca. $50 \mathrm{~nm}$ (less often up to ca. $400 \mathrm{~nm}$ ), which were periodically located all over the surface of the coating. The oxidation process, which was partially accompanied by swelling, could have caused such an occurrence. This mechanism did not appear in the whole volume of the coating, but only in small regions.

v. The $\mathrm{N}_{2}-\mathrm{SiH}_{4}$-Ar gas mixture used during the deposition process of the WC/C coatings protects against significant degradation up to a temperature of $800{ }^{\circ} \mathrm{C}$.

Author Contributions: P.H. deposited WC/C coatings; K.K. and L.K. evaluated SEM analysis of structure of coatings and roughness by AFM; D.K. prepared the experiment and wrote this manuscript; M.K. performed XPS testing of chemical analysis and selected atomic groups of the tested structures; M.T. and J.J. assisted with hardness measurements and analyzed data and prepared samples for deposition of coatings; J.H. and L.R. conducted the pin-on-disc testing. All authors have read and agreed to the published version of the manuscript.

Funding: This research was funded by the Ministry of Education, Science, Research and Sport of the Slovak Republic VEGA No. 1/0432/17 and of the Slovak Research and Development Agency APVV-17-0258 and APVV-16-0359 and the APC was funded by the Slovak Research and Development Agency.

Institutional Review Board Statement: Not applicable.

Informed Consent Statement: Not applicable.

Data Availability Statement: Data sharing is not applicable to this article.

Acknowledgments: This research was financially supported by the Ministry of Education, Science, Research and Sport of the Slovak Republic (VEGA 1/0432/17). It is also the result of the projects KEGA 023TUKE-4/2020 and APVV-17-0258.

Conflicts of Interest: The authors declare no conflict of interest.

\section{References}

1. El Mrabet, S.; Abad, M.D.; Sánchez-López, J.C. Identification of the wear mechanism on WC/C nanostructured coatings. Surf. Coat. Technol. 2011, 206, 1913-1920. [CrossRef]

2. Czyzniewski, A. Deposition and some properties of nanocrystalline WC and nanocomposite WC/a-C:H coatings. Thin Solid Films. 2003, 433, 180-185. [CrossRef]

3. Keller, G.; Barzen, I.; Erz, E.; Dötter, W.; Ulrich, S.; Juang, K.; Ehrhardt, H. Crystal structure, morphology and composition of magnetron sputtered tungsten carbide films. Fresenius' J. Anal. Chem. 1991, 341, 349-352. [CrossRef]

4. Barényi, I.; Majerík, J.; Pokorný, Z.; Sedlák, J.; Bezecný, J.; Dobrocký, D.; Jaroš, A.; Eckert, M.; Jambor, J.; Kusenda, R. Material and technological investigation of machined surfaces of the OCHN3MFA steel. Met. Mater. Kov. Mater. 2019, 57, 131-142. [CrossRef]

5. Bhushan, B.; Gupta, B.K. Handbook of Tribology: Materials, Coatings, and Surface Treatments; McGraw-Hill: New York, NY, USA, 1991; p. 1643. 
6. Makowka, M.; Pawlak, W.; Konarski, P.; Wendler, B. Hydrogen content influence on tribological properties of nc-WC/a-C:H coatings. Diam. Relat. Mater. 2016, 67, 16-25. [CrossRef]

7. Lofaj, F.; Kabátová, M.; Klich, M.; Vaňa, D.; Dobrovodský, J. The comparison of structure and properties in DC magnetron sputtered and HiPIMS W-C:H coatings with different hydrogen content. Ceram. Int. 2019, 45, 9502-9514. [CrossRef]

8. Horňák, P.; Kottfer, D.; Kaczmarek, L.; Kianicová, M.; Balko, J.; Rehák, F.; Pekarčíková, M.; Čižnár, P. The effect of pressure, bias voltage and annealing temperature on N2 and N2 + SiH4 doped WC/C DC magnetron sputtered layers. Ceram. Silikáty 2018, 62, 97-107. [CrossRef]

9. Abad, M.D.; Muñoz-Márquez, M.A.; El Mrabet, S.; Justo, A.; Sánchez-López, J.C. Tailored synthesis of nanostructured WC/a-C layers by dual magnetron sputtering. Surf. Coat. Technol. 2010, 204, 3490-3500. [CrossRef]

10. Zhou, S.G.; Wang, L.; Wang, S.C.; Xue, Q. Comparative study of simplex doped nc-WC/a-C and duplex doped nc-WC/a-C(Al) nanocomposite layers. Appl. Surf. Sci. 2011, 257, 6971-6979. [CrossRef]

11. Kosinskiy, M.; Ahmed, S.I.U.; Liu, Y.; Gubisch, M.; Mastylo, R.; Spiess, L.; Schaefer, J.A. Friction and wear properties of WC/C nano-scale multilayer layers on technical surfaces. Tribol. Lett. 2011, 44, 89-98. [CrossRef]

12. Agudelo-Morimitsu, L.C.; DeLaRoche, J.; Escobar, D.; Ospina, R.; Restrepo-Parra, E. Substrate heating and post-annealing effect on tungsten/tungsten carbide bilayers grown by non-reactive DC magnetron sputtering. Ceram. Int. 2013, 39, 7355-7365. [CrossRef]

13. Novák, M.; Lofaj, F.; Hviščová, P.; Podoba, R.; Haršáni, M.; Sahul, M.; Čaplovič, L'. Nanohardness of DC magnetron sputtered W-C layers as a function of composition and residual stresses. Key Eng. Mater. 2015, 662, 107-110. [CrossRef]

14. Park, Y.S.; Park, Y.; Jung HJung, T.H.; Lim, D.G.; Choi, W.S. Tribological properties of a-C:W film deposited by radio frequency magnetron Co-sputtering method. Thin Solid Film. 2012, 521, 107-111. [CrossRef]

15. Li, Y.; Zhang, A.; Li, G. The influence of microstructure on mechanical property of polytypic TiC/WC nanomultilayers. Vacuum 2015, 117, 23-26. [CrossRef]

16. Zhao, H.; Ni, Z.; Ye, F. Effect of carbon content on structure and properties of WCN coatings prepared by RF magnetron sputtering. Surf. Coat. Technol. 2016, 287, 129-137. [CrossRef]

17. Horňák, P.; Kottfer, D.; Kaczmarek, L.; Kyziol, K.; Vavro, J.; Klich, M.; Trebuňa, J.; Vrabel', M.; Franková, M. Microstructure and mechanical properties of annealed WCC coatings deposited with di_erent gas mixtures in an RFMS process. Ceram. Silikáty 2019, 63, 213-222. [CrossRef]

18. Lofaj, F.; Kvetková, L.; Hviščová, P.; Gregor, M.; Ferdinandy, M. Reactive processes in the high target utilization sputtering (HiTUS) W-C based coatings. J. Eur. Ceram. Soc. 2016, 36, 3029-3040. [CrossRef]

19. Gesheva, K.A.; Vlakhov, E.S.; Stoyanov, G.I.; Beshkod, G.D.; Marinov, M. Deposition CVD-tungsten and characterization of and tungsten carbonitrides on (100) Si. Ceram. Int. 1996, 22, 87-89. [CrossRef]

20. Neto, M.A.; Silva, E.L.; Fernandes, A.J.S.; Oliveira, F.J.; Silva, R.F. Deposition of WC/a-C nanocomposite thin films by hot-filament CVD. Surf. Coat. Technol. 2011, 206, 103-106. [CrossRef]

21. Gesheva, K.; Abrosimova, V.; Beshkov, G. CVD carbonyl thin films of tungsten and molybdenum and their silicides-a good alternative to CVD fluoride tungsten technology. J. Phys. 1991, 2, 865-871. [CrossRef]

22. Ferdinandy, M.; Lofaj, F.; Dusza, J.; Kottfer, D. Preparation of WC coatings by $\mathrm{W}(\mathrm{CO})_{6}$ decomposition using PE CVD method. Chem. Lett. Chem. Listy 2011, 105, 442-444. (In Slovak)

23. Lofaj, F.; Ferdinandy, M.; Cempura, G.; Horňák, P.; Vnouček, M. Transfer film in a friction contact in the nanocomposite WC-C coatings. J. Aust.Ralian Ceram. Soc. 2013, 49, 34-43.

24. Lofaj, F.; Ferdinandy, M.; Kottfer, D.; Dusza, J.; Němeček, J. Tribological properties of the Cr-C and W-C based PECVD nanocomposite coatings (CD room). In Proceedings of the 11th Conference (ECERS 2009), Krakow, Poland, 20-25 June 2009; pp. 642-646.

25. Ferdinandy, M.; Kottfer, D.; Hviščová, P.; Balko, J. Preparation of $\mathrm{WCrC}$ coatings by $\mathrm{W}(\mathrm{CO})_{6}$ and $\mathrm{Cr}(\mathrm{CO})_{6}$ decomposition using PECVD method. In Proceedings of the 14th Conference Layers and Coatings, Trenčianska Teplá, Slovakia, 19-20 October 2015; pp. 87-89. (In Slovak).

26. Garner, M.L.; Chandra, D.; Lau, K.H. Low-temperature vapor pressures of W, Cr-, and Co-carbonyls. J. Phase Equilibria 1995, 16, 24-29. [CrossRef]

27. Horňák, P.; Kottfer, D.; Kyziol, K.; Trebuňová, M.; Majerníková, J.; Kaczmarek, L.; Trebuňa, J.; Hašul', J.; Pal’o, M. Microstructure and Mechanical Properties of Annealed WC/C PECVD Coatings Deposited Using Hexacarbonyl of W with Different Gases. Materials 2020, 13, 3576. [CrossRef] [PubMed]

28. Rezuchina, T.N.; Švyrev, V.V. Saturated vapor pressure and sublimation temperature of Mo(CO) 6 and $\mathrm{W}(\mathrm{CO})_{6}$. Vestn. Mosk. Univ. 1952, 6, 41-46. (In Russian)

29. Lu-Steffes, O.J.; Sakidja, R.; Bero, J.; Perepezko, J.H. Multicomponent coating for enhanced oxidation resistance of tungsten. Surf. Coat. Technol. 2012, 207, 614-619. [CrossRef]

30. Chellappa, R.; Chandra, D. Assessment of vapor pressure data of solid metal carbonyls. J. Chem. Thermodyn. 2005, 37, 377-387. [CrossRef]

31. Usoltsev, I.; Eichler, R.; Wang, Y.; Even, J.; Yakushev, A.; Haba, H.; Asai, M.; Brand, H.; Di Nitto, A.; Düllmann, C.E.; et al. Decomposition studies of group 6 hexacarbonyl complexes. Part 1: Production and decomposition of $\mathrm{Mo}(\mathrm{CO})_{6}$ and $\mathrm{W}(\mathrm{CO})_{6}$. Radiochim. Acta 2015, 104, 141-151. [CrossRef] 
32. Erokhin, M.N.; Kazantsev, S.P.; Chupyatov, N.N. Wear-resistance of carbide-containing chrome coatings obtained from gas phase. Vestn. Fed. State Eduation Inst. High Prof. Educ. Mosc. State Agroeng. Univ. Named VP Goryachkin 2017, 5, 48-53. (In Russian)

33. Toshiro Maruyama, T.; Akagi, H. Chromium Oxide Thin Films Prepared by Chemical Vapor Deposition from Chromium Acetylacetonate and Chromium Hexacarbonyl. J. Electrochem. Soc. 1996, 143, 1955-1957. [CrossRef]

34. Wang, J.W.; Gupta, A.; Klein, T.M. Plasma enhanced chemical vapor deposition of $\mathrm{Cr}_{2} \mathrm{O}_{3}$ thin films using chromium hexacarbonyl $\left(\mathrm{Cr}(\mathrm{CO})_{6}\right)$ precursor. Thin Solid Film. 2008, 516, 7366-7372. [CrossRef]

35. Douard, A.; Maury, F. Chromium-based coatings by atmospheric chemical vapor deposition at low temperature from $\mathrm{Cr}(\mathrm{CO})_{6}$. Surf. Coat. Technol. 2005, 21, 1407-1412. [CrossRef]

36. Sagalovych, A.; Popov, V.; Sagalovych, V.; Dudnik, S.; Popenchuk, R. Development of the chemical vapor deposition process for applying molybdenum coatings on the components in assembly and engine construction. East. Eur. J. Enterp. Technol. 2020, 2 6-15. [CrossRef]

37. Lofaj, F.; Kaganowskyy, Y.S. Kinetics of WC-Co oxidation accompanied by swelling. J. Mater. Sci. 1995, 30, 1811-1817. [CrossRef]

38. Chu, P.K.; Li, L. Characterization of amorphous and nanocrystalline carbon films. Mater. Chem. Phys. 2006, 96, 253-277. [CrossRef]

39. Krasovskii, P.V.; Malinovskaya, O.S.; Samokhin, A.V.; Blagoveshchenskiy, Y.V.; Kazakov, V.A.; Ashmarin, A.A. XPS study of surface chemistry of tungsten carbides nanopowders produced through DC thermal plasma/hydrogen annealing process. Appl. Surf. Sci. 2015, 339, 46-54. [CrossRef]

40. Huang, L.; Yang, J.; Zhou, W.; Liu, K.; Zhu, D.; Chen, Y. Nanoscale tungsten nitride/nitrogen-doped carbon as an efficient non-noble metal catalyst for hydrogen and oxygen recombination at room temperature in nickel-iron batteries. R. Soc. Chem. Adv. 2018, 8, 35343. [CrossRef]

41. X-ray Photoelectron Spectroscopy (XPS) Reference Pages, Tungsten. Available online: http://www.xpsfitting.com/2009/04/ tungsten.html (accessed on 12 August 2021). 